\title{
ARTIKELEN
}

\section{Neurowetenschappelijke kennis en de jeugdstrafrechtsketen}

\author{
Liza Cornet \& Katy de Kogel
}

Wat kan de justitiële praktijk met neurowetenschappelijke kennis en methoden? Het WODC inventariseerde deze vraag in het rapport Neurowetenschappelijke toepassingen in de jeugdstrafrechtketen, dat begin 2017 verscheen. Bij de openbaarmaking van het rapport tuimelden de grote nieuwsbronnen over elkaar heen. ${ }^{1}$ De positieve media-aandacht die het rapport kreeg is om meerdere redenen opvallend. Het geeft aan dat men tegenwoordig openstaat voor onderzoek naar biologische factoren en crimineel gedrag, iets wat veertig jaar geleden 'not done' was. Tegelijkertijd illustreert de grote 'nieuwswaarde' van het onderwerp ook dat dit vakgebied nieuw is en dat het idee dat biologische factoren een rol spelen bij crimineel gedrag nog niet algemeen geaccepteerd is. In dit artikel wordt naar aanleiding van het WDOC-rapport op toegankelijke en bondige wijze beschrijven wat we weten over neurobiologie en antisociaal gedrag en op welke manier de justitiele praktijk deze kennis kan benutten. ${ }^{2}$ Hoewel het WODC-rapport zich richt op de jeugdstrafrechtsketen, zijn de resultaten onzes inziens voor de gehele strafrechtsketen interessant.

\section{Wat weten we over de relatie tussen neurobiologie en antisociaal gedrag?}

De laatste decennia is veel onderzoek gedaan naar neurobiologische kenmerken bij mensen met (ernstig) antisociaal gedrag. Met neurobiologische kenmerken bedoelen we allerlei biologische processen in het menselijk lichaam, zoals hartslag, hersenfunctioneren en hormoonspiegels. Biocriminologisch onderzoek toont aan dat bepaalde neurobiologische kenmerken of problemen relatief vaker voorkomen bij personen met ernstig antisociaal gedrag vergeleken met controleperso-

* $\quad$ L.J.M. Cornet MSc is postdoc onderzoeker aan de Universiteit Twente. Zij was ten tijde van het schrijven van dit artikel nog werkzaam als onderzoeker bij het Wetenschappelijk Onderzoek- en Documentatiecentrum, ministerie van Justitie en Veiligheid. Dr. C.H. de Kogel is senior wetenschappelijk medewerker bij het Wetenschappelijk Onderzoek- en Documentatiecentrum, ministerie van Justitie en Veiligheid.

1 O.a. NOS-journaal 18.00-24.00, 2 februari over 'Neurowetenschappelijke toepassingen in de jeugdstrafrechtketen'; de Volkskrant, 'Onderzoekers Justitie: kijk bij behandeling jonge crimineel ook naar biologische factoren'; interview BNR Nieuwsradio 8.30, 2 februari 2017; interview 3FM 8.00, 2 februari 2017; interview Radio 1 journaal 8.00, 2 februari 2017.

2 Delen in deze publicatie zijn direct of indirect afgeleid van het WODC-rapport Neurowetenschappelijke toepassingen in de jeugdstrafrechtketen: Een inventarisatie van instrumenten, preventie en interventie. 
nen die geen ernstig antisociaal gedrag laten zien (onder andere Van Goozen e.a. 2007; Yang \& Raine 2009). Maar over welke neurobiologische factoren hebben we het dan eigenlijk?

Om deze vraag te beantwoorden verzamelden we voor het WODC-rapport overzichtsstudies (reviews en meta-analyses). Belangrijk om hierbij op te merken is dat daarmee de hierna volgende bevindingen een algemene indruk geven en de resultaten niet uitputtend zijn. Grofweg blijken de volgende vijf domeinen het meest onderzocht te zijn in relatie tot antisociaal gedrag: hersenfunctioneren en anatomie, hormoonspiegels, psychofysiologie, neurotransmitters en genetica. In figuur 1 zijn de belangrijkste bevindingen uit deze studies in een schematisch overzicht weergegeven. De bevindingen hangen nauw samen met twee vaak aangehaalde theoretische kaders, te weten: de prefrontale-disfunctietheorie en de lagearousaltheorie.

Volgens de prefrontale-disfunctietheorie worden personen met ernstig antisociaal gedrag vaak gekenmerkt door afwijkingen in zowel de bouw als de werking van met name het voorste deel van de hersenen. Schade aan of een minder voorspoedige ontwikkeling van dit deel van de hersenen kan leiden tot problemen met de zogeheten 'executieve functies'. Deze functies hebben te maken met het vermogen tot zelfregulatie - het sturen van het eigen gedrag en denken. Vaardigheden die hieronder vallen zijn onder andere het richten van de aandacht, het plannen van activiteiten, het beheersen van impulsen en emoties en het overzien van consequenties van gedrag. Verschillende meta-analyses laten zien dat individuen die ernstig antisociaal gedrag vertonen, over het algemeen slechter presteren op neuropsychologische testen die een beroep doen op de genoemde executieve functies vergeleken met controlepersonen zonder antisociaal gedrag (onder andere Ogilvie e.a. 2011).

Ook wat betreft chemische substanties in het brein - neurotransmitters - worden afwijkingen gevonden bij personen met ernstig antisociaal/agressief gedrag. Zo is er bewijs voor een (bescheiden) relatie tussen een verlaagd serotonineniveau en een verhoogde kans op agressie, woede en gewelddadigheid (zie meta-analyse Duke e.a. 2013; Narvaes \& Martins de Almeida 2014). Serotonine is een neurotransmitter die wordt afgegeven door zenuwcellen in de hersenen en is betrokken bij onder andere de regulatie van slaap, eetlust en stemming. Het verband tussen serotonine en agressief gedrag is echter complex; onder andere het soort agressief gedrag (bijvoorbeeld proactief of reactief), het type agressief gedrag (psychopathie, impulsiviteit) en de plek in het brein waar serotonine effect heeft, spelen een rol.

Uit verschillende meta-analyses blijkt dat een lage hartslag in rust beschouwd kan worden als een van de meest robuuste psychofysiologische correlaten van antisociaal gedrag (meta-analyse door Portnoy en Farrington (2015)). Volgens de lagearousaltheorie worden personen met ernstig antisociaal gedrag vaak gekenmerkt door een lagere activiteit van het zenuwstelsel, vooral in het fysiologische stresssysteem. Dit uit zich onder meer in een lage rusthartslag. Eén mogelijke verklaring voor de relatie tussen verminderde fysiologische arousal en antisociaal gedrag 
heeft te maken met sensation seeking (Portnoy e.a. 2014). Volgens dit principe zou verminderde fysiologische activiteit onaangenaam zijn. Een verhoogde fysiologische arousal kan worden uitgelokt door spanning op te zoeken. Dit leidt ertoe dat individuen met een laag arousalniveau eerder geneigd zijn grenzen op te zoeken, bijvoorbeeld door het plegen van delicten.

Antisociaal gedrag wordt, naast hartslag, in verband gebracht met afwijkingen in huidgeleiding. Huidgeleiding verwijst naar de elektrische geleiding van de huid die wordt beïnvloed door de mate van zweetproductie, bijvoorbeeld op de handen. Wanneer er meer zweet wordt geproduceerd, neemt de huidgeleiding toe. De relatie tussen huidgeleiding en antisociaal gedrag is echter minder duidelijk dan die tussen hartslag in rust en antisociaal gedrag.

In lijn met de lage-arousaltheorie laat onderzoek naar hormoonspiegels zien dat het stresshormoon cortisol over het algemeen verlaagd is bij personen met antisociale gedragsproblematiek (onder andere Alink e.a. 2008). Er is echter ook een groep bij wie het juist verhoogd is. Daarnaast is er bewijs voor een positief maar zwak verband tussen testosteron en problematisch antisociaal/agressief gedrag bij jongeren en volwassenen. Onderzoek laat verder zien dat de verhouding tussen cortisol en testosteron belangrijk is als het gaat om antisociaal/agressief gedrag (Terburg, Morgan \& Van Honk 2009). Het lijkt erop dat een hoog testosterongehalte enerzijds individuen gevoeliger maakt voor beloningen, en een lage cortisolconcentratie anderzijds zorgt voor minder angstgevoeligheid (Van der Gronde e.a. 2014). De relatie tussen agressie en 'laag cortisol/hoog testosteron' wordt sterk beïnvloed door onder andere geslacht en mate van psychopathie (Rosell \& Siever 2015).

Tot slot, onderzoek laat zien dat ernstig antisociaal gedrag voor 40 tot $60 \%$ toegeschreven kan worden aan genetische factoren (Beaver, Ratchford \& Ferguson 2009; Moffitt 2005). Genen coderen voor eiwitten. Die eiwitten vormen weer de bouwstoffen voor de cellen in ons lichaam, maar ook voor bijvoorbeeld neurotransmitters (waarmee hersencellen communiceren) en hormonen (waardoor de hersenen ook met de rest van het lichaam kunnen communiceren en andersom). Neurotransmittersystemen en hormonen dragen bij aan bepaalde neigingen, zoals de neiging tot agressief gedrag. Onze genen dragen dus zelf niet direct bij aan gedragsproblemen, maar aan een 'gevoeligheid voor', die in combinatie met omgevingsfactoren kan leiden tot bepaald (grensoverschrijdend) gedrag. Hoewel veel inspanningen zijn gedaan om te ontdekken welke genen dan precies bijdragen aan het ontstaan van antisociaal gedrag, lijkt geen enkel individueel gen noemenswaardig bij te dragen aan de variantie in crimineel gedrag (Goldman \& Ducci 2007). Wel kunnen we concluderen dat er meerdere genen met elk kleine effecten betrokken zijn bij het risico op antisociaal gedrag en dat niet alléén genen, maar een complexe interactie tussen genen en omgeving bijdraagt aan het ontstaan van antisociaal en agressief gedrag.

$\mathrm{Al}$ met al hebben we op dit momenteel behoorlijk wat kennis over de relatie tussen neurobiologische factoren en antisociaal gedrag. Die kennis wordt op dit moment nog nauwelijks benut in de justitiële praktijk. In de volgende paragrafen 
Figuur 1 Schematische samenvatting van de belangrijkste bevindingen op het gebied van neurowetenschappen en antisociaal gedrag (bron: WODC rapport)

\section{Problemen met excecutieve functies zoals zelfbeheersing en planning}
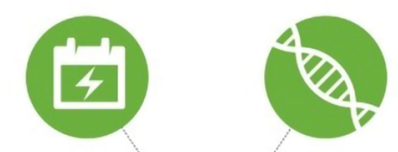

Minder activiteit en volume in bepaalde hersengebieden
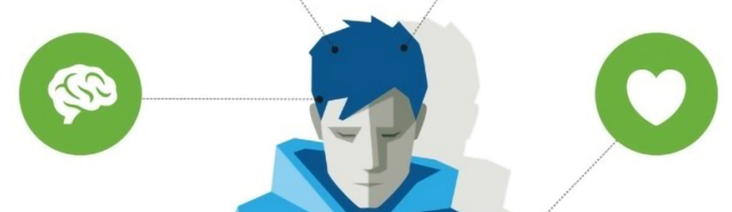

Verlaagde hartslag in rust cortisolen testosteronconcentraties

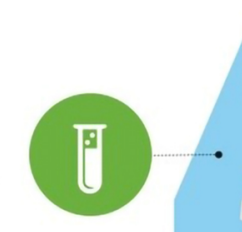

Voorbeeld: personen met antisociaal gedrag kunnen minder vatbaar voor straf zijn, doordat hun stresssysteem minder sterk reageert.

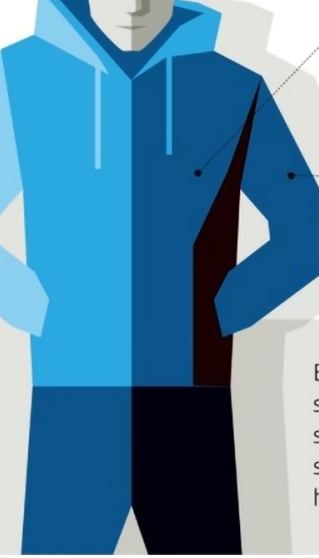

Een minder gevoelig stresssysteem uit zich in een lage hartslag, lage concentraties van het stresshormoon cortisol en minder hersenactiviteit in de amygdala.

beschrijven we op welke manier het biologisch perspectief op antisociaal gedrag een aanvulling kan zijn voor de justitiële praktijk op het meer gangbare psychosociale perspectief.

\section{Neurowetenschappelijke methoden en interventies}

Van oudsher domineren voornamelijk psychosociale perspectieven de manier waarop we antisociaal gedrag beschouwen en aanpakken. Die invloeden zijn terug te zien in bijvoorbeeld de screenings- en risicotaxatie-instrumenten die in de jeugdstrafrechtsketen worden gebruikt. Zo bepaalt de politie in het begin van de keten het recidiverisico op basis van statistische gegevens (zoals iemands delictsgeschiedenis), en wordt verderop in de keten een uitgebreider risicoprofiel gemaakt met behulp van informatie over onder andere de sociale omgeving. Welke informatie precies verzameld wordt in de jeugdstrafrechtsketen en met welke instrumenten dat gebeurt, wordt bepaald door het Landelijk Kader (Vogelvang, Krooi \& Van den Braak 2006). Het Landelijk Kader is opgesteld vanuit het Risk-Need-Responsivity-model, een model ten aanzien van crimineel gedrag waaraan voornamelijk psychologische en sociale perspectieven ten grondslag lig- 
gen. De richtlijnen voor de vanuit het Landelijk Kader voorgeschreven instrumenten hebben betrekking op verschillende fases in de jeugdstrafrechtsketen: voor screening (op het moment dat een jongere opgepakt wordt door de politie), ter diagnostisering (nadat een proces-verbaal is gemaakt) en voor advisering en indicering (wanneer er wordt gevonnist) (Van der Put e.a. 2011). De psychosociale inslag van het Landelijk Kader heeft ertoe geleid dat neurobiologische factoren tot op heden geen of nauwelijks een rol spelen in het instrumentarium van de jeugdstrafrechtsketen. Veel meer aandacht gaat uit naar psychosociale factoren, zoals problemen op het werk, de school of thuis. De in de vorige paragaaf geschetste onderzoeken laten zien dat neurobiologische kenmerken wel degelijk een deel van de puzzelstukjes vormen voor het begrijpen van antisociaal gedrag.

Ook bij de typen interventiemethoden in de strafrechtsketen zien we het monopolie van psychosociale ideeën terug. Veel in Nederland toegepaste justitiële gedragsinterventies zijn gebaseerd op een cognitief-gedragstherapeutische benadering. Cognitieve gedragstherapieën beogen veranderingen in denkpatronen en gedrag tot stand te brengen. Er zijn echter wisselende resultaten gevonden als het gaat om het veranderen van crimineel gedrag en het verminderen van recidive door dit soort interventieprogramma's (onder andere Lipsey \& Cullen 2007; Verweij, Tollenaar \& Wartna, 2016). Daarnaast is onduidelijk in hoeverre deze interventies ook effect hebben op de hiervoor beschreven neurobiologische tekorten. Het lijkt daarom zinvol om het perspectief te verbreden en een verklaring voor verschillen in behandelresponsiviteit mede te zoeken vanuit een andere invalshoek. Wij veronderstellen dat het neurobiologisch perspectief een aanvullende invalshoek zou kunnen zijn op het psychosociale perspectief dat nu domineert.

\section{Neuropsychologische testen als aanvulling op het instrumentarium in de strafrechtsketen}

De term 'neurowetenschappelijke meetmethoden' roept al snel een beeld op van het meten van hersenactiviteit of afname van bloed. Toch zijn er ook minder invasieve meetmethoden die in biocriminologisch onderzoek gebruikt worden. Zoals een hartslagmeter om de rusthartslag in kaart te brengen, een wattenstaafje om speeksel af te nemen voor hormoonanalyse, of neuropsychologische testen om indirect het hersenfunctioneren in kaart te brengen. Van deze verschillende meetmethoden lijken neuropsychologische testen het meest eenvoudig te gebruiken in de justitiële praktijk. Tijdens dit soort testen wordt personen vaak gevraagd een opdracht uit te voeren, bijvoorbeeld om kaarten te categoriseren of zo snel mogelijk op bepaalde signalen te reageren. Figuur 2 betreft een voorbeeld van een neuropsychologische test. Neuropsychologische testen zijn zo ontwikkeld dat ze vermogens meten, zoals zelfbeheersing en planningsvaardigheden, waarvan verondersteld wordt dat ze een beroep doen op bepaalde hersenfuncties of circuits. In tegenstelling tot MRI-scans, waarmee direct in de hersenen gekeken kan worden, geven neuropsychologische testen indirect een beeld van hersenfuncties, afgeleid uit de prestaties van de persoon op de test. 
Figuur 2 De Wisconsin Cart Sorting Test (WCST). Tijdens de WCST wordt deelnemers gevraagd een stapel kaarten te sorteren volgens een bepaalde regel die onverwacht verandert tijdens de taak. De testafnemer geeft telkens aan of de gesorteerde kaart goed of fout is en op basis van die feedback is het aan de deelnemer om te achterhalen welke regel op dat moment geldt. Dit is een veelgebruikte neuropsychologische test, die onder andere cognitieve flexibiliteit meet, het vermogen om reacties flexibel aan te passen als de omgeving verandert.
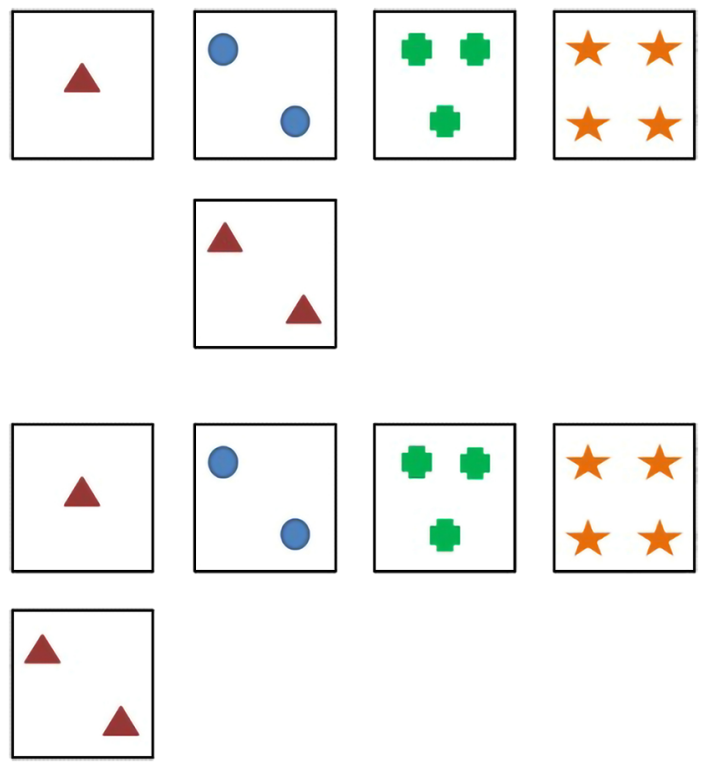

Zoals hiervoor beschreven, hebben personen met ernstig antisociaal gedrag vaker problemen met het presteren op neuropsychologische testen vergeleken met gezonde controlegroepen. Bínnen groepen personen met antisociaal gedrag lijken er echter ook verschillen te bestaan als het gaat om de prestatie op neuropsychologische testen. Zo blijkt bijvoorbeeld dat delinquenten met reactieve agressie slechter presteren op dit soort testen dan delinquenten die gekenmerkt worden door proactieve agressie (onder andere Broomhall 2005; Hoaken, Allaby \& Earle 2007). Dit gegeven kan handvatten bieden voor differentiatie in bejegening en interventie bij delinquenten met verschillende typen agressief gedrag. Op basis van literatuur en gesprekken met experts en praktijkdeskundigen uit de jeugdstrafrechtsketen lijken de volgende domeinen het meest relevant te zijn in relatie tot jeugdcriminaliteit: (ruimtelijk) werkgeheugen, aandacht, zelfregulatie (gerelateerd: impulsbeheersing, inhibitie), emotieregulatie (gerelateerd: agressieregulatie), empathie en cognitieve flexibiliteit. Voor elk van deze domeinen zijn veel neuropsychologische testen beschikbaar (zie het WODC-rapport voor voorbeelden). 
Stel dat dit soort testen meer gebruikt zou worden in de justitiële praktijk, wat zouden we dan met de uitkomst op deze testen kunnen?

Allereerst dragen neuropsychologische testen bij aan het ontwikkelen van een 'biopsychosociaal' profiel van een individu. Door naast psychologische en sociale informatie uit vragenlijsten en interviews óók neuropsychologische testen af te nemen krijgen we een rijker beeld van de kenmerken van een persoon. Deze informatie kan vervolgens gebruikt worden in bijvoorbeeld de bejegening, maar ook voor de inschatting welke interventie het best aansluit bij de kenmerken van deze persoon. Een relevant onderzoek in dit verband is gedaan bij volwassen gedetineerden die de CoVa-training (cognitieve vaardigheden) volgden (Cornet e.a. 2015). Het blijkt dat degenen die relatief slecht presteren op een neuropsychologische aandachttest (de D2-test), een hogere kans hebben om voortijdig met de training te stoppen. Een interessante bevinding, zeker omdat de neuropsychologische test een sterkere voorspellende waarde blijkt te hebben in relatie tot behandeluitval dan zelfgerapporteerde behandelmotivatie, een psychologisch construct waar in de praktijk veel waarde aan wordt gehecht.

\section{Neurowetenschappelijke kennis en justitiële interventiemethoden}

Neurowetenschappelijke kennis draagt dus wellicht bij aan een betere voorspelling van wie wel en wie niet zal profiteren van gedragsinterventie, maar het neurowetenschappelijk perspectief biedt onzes inziens ook de mogelijkheid om na te denken over alternatieve, op neurowetenschap geïnspireerde behandelmethoden. Zoals de term neurowetenschappelijke methode al snel een beeld oproept, doen neurowetenschappelijke behandelvormen dat ook. Toch is het een misvatting dat neurowetenschappelijke interventies alleen betrekking hebben op het veranderen van hersenactiviteit, medicatie of inhaleren van hormonen. Het is interessant dat bestaande justitiële gedragsinterventies ook effect kunnen hebben op neurobiologische processen. Zo blijkt een gedragsinterventie voor kinderen die pestgedrag vertonen, naast verbetering op gedragsniveau ook te leiden tot een 'normalisering' van het stresshormoon cortisol (onder andere Nickel e.a. 2006). In zekere zin zouden bestaande gedragsinterventies ook als neurowetenschappelijke behandelmethoden kunnen worden beschouwd, omdat ze in potentie effect hebben op onderliggende neurobiologische processen. Dit suggereert ook dat neurowetenschappelijke methoden gebruikt zouden kunnen worden als aanvullende methoden om de effectiviteit van een bestaande behandelmethoden in kaart te brengen. Maar neurowetenschappelijke inzichten kunnen ook benut worden om alternatieve interventiemethoden toe te voegen aan het huidige behandelaanbod. In het navolgende bespreken we twee verschillende, op neurowetenschappelijke kennis geïnspireerde behandelmethoden: neuropsychologische trainingen en voedingssupplementen.

Het doel van een neuropsychologische training is om bepaalde hersenfuncties te activeren en uiteindelijk te verbeteren. Zoals hiervoor beschreven, worden binnen groepen personen met antisociale trekken vaak problemen in complexe functies gevonden, zoals plannen, werkgeheugen en emotieherkenning. Het trainen van deze complexe, executieve functies zou in potentie een positief effect op gedrag 
kunnen hebben. Een interessante studie in dit kader is die van Baskin-Sommers, Curtin en Newman (2015). Zij onderzochten het effect van twee typen neuropsychologische trainingen bij volwassen gevangenen. Gevangenen werden getraind in ofwel het verbeteren van aandacht voor context en emotionele informatie, ofwel het verbeteren van inhibitie: het vermogen om een handeling of bepaald gedrag af te remmen of te stoppen. De gedachte was dat gevangenen met psychopathische trekken, die vooral moeite hebben met het letten op informatie uit de omgeving, meer baat zouden hebben bij de aandachtstraining, terwijl gevangenen met externaliserende trekken, die vooral moeite hebben met het beheersen van impulsen, juist meer zouden profiteren van de inhibitietraining. Na de trainingsperiode lieten beide groepen delinquenten verbeteringen zien op hun specifieke probleemgebied wanneer zij de daarop gerichte training hadden ondergaan. Opvallend hierbij was dat delinquenten niet alleen verbeteringen lieten zien op getrainde testen, maar ook op niet-getrainde testen die betrekking hadden op vergelijkbare neuropsychologische functies. De resultaten laten dus zien dat de verbeteringen niet testspecifiek zijn, maar betrekking hebben op het hele onderliggende probleemgebied.

Een andere neuropsychologische training betreft het trainen van emotieherkenning bij jeugdige delinquenten. Uit de literatuur blijkt dat emotieherkenning (bijvoorbeeld het herkennen van emotionele gezichtsuitdrukkingen) vaak aangedaan is bij mensen met antisociale trekken en mogelijk vooral bij mensen met psychopathische/kille persoonlijkheidstrekken (Bons e.a 2013; Marsh \& Blair 2008). In een studie werd de effectiviteit van een emotieherkenningstraining (Facial Affect Recognition, FAR) onderzocht (Hubble e.a 2015). Jeugdige delinquenten tussen 12 en 18 jaar oud werden gedurende twee weken getraind in het herkennen van emoties. De training bestond onder andere uit het benoemen van emoties, het beschrijven van een gebeurtenis waarbij zij zelf die emotie ervoeren en het nadoen van een emotie in de spiegel. Bij de groep delinquenten die aan deze training deelnam, trad verbetering op in het herkennen van de emoties angst, verdriet en woede, in vergelijking met een groep delinquenten die de training niet onderging. Daarnaast begingen delinquenten die aan de training deelnamen significant minder geweldsdelicten in de zes maanden na de training dan voor de training. Er waren echter geen verschillen in het aantal nieuwe delicten tussen beide groepen.

Vorenstaande studies laten de potentie zien van gerichte training op neuropsychologische functies ter vermindering van antisociaal gedrag.

Wat betreft voedingssupplementen is er enig wetenschappelijk bewijs dat met name omega-3/6-vetzuren, mineralen en vitamines als toevoeging aan het dieet kunnen leiden tot vermindering van agressief gedrag. Omega-3/6-vetzuren spelen waarschijnlijk een rol in de communicatie tussen hersencellen (Benton 2007), en omega-3 beïnvloedt mogelijk de afgifte van serotonine in de frontale cortex (Patrick \& Ames 2015). Overzichtsstudies tonen een verband aan tussen het toevoegen van vetzuren aan het dieet en een vermindering van agressief gedrag (Benton 2007; Gow \& Hibbeln 2014). Enkele van de daarin opgenomen studies richtten zich op gedetineerden. Gesch en collega's (2002) en Zaalberg en collega's 
(2010) vonden een afname van agressieve incidenten onder volwassen gedetineerden na het toevoegen van voedingssupplementen met vitamines, mineralen en omega-3/6-vetzuren aan het dieet. In een andere studie onderzochten Raine en collega's (2015) de langetermijneffecten van omega-3-vetzuren op de mate van antisociaal gedrag bij kinderen en adolescenten tussen de 8 en 16 jaar oud. Zij rapporteerden dat zes maanden na afloop van het experiment de kinderen en adolescenten volgens hun ouders minder externaliserend en agressief gedrag vertoonden. Hoewel de ouders zelf geen supplementen kregen, werd ook bij hen een significante vermindering in antisociaal en reactief agressief gedrag waargenomen. Een verklaring hiervoor kan liggen in de wederkerige relatie tussen ouder en kind, waarbij zij verbeteringen in elkaars gedrag wederzijds beïnvloeden (Raine e.a. 2015). Naast omega-3 hebben mineralen en/of vitamines mogelijk ook een positieve invloed op de mate van agressief gedrag. Schoentaler en collega's (1997) beschrijven een afname in gewelddadig gedrag onder jeugdige gevangenen door supplementen die wel vitamines en mineralen bevatten, maar geen vetzuren.

\section{Van wetenschap naar praktijk}

In dit artikel hebben we laten zien dat neurowetenschappelijke methoden en kennis in potentie een verrijking kunnen zijn voor de justitiële praktijk, maar het daadwerkelijk gebruik van deze methoden en kennis vraagt wel om de juiste expertise en reële verwachtingen. Een gebrek aan kennis over de mogelijkheden en beperkingen van neurowetenschappelijke kennis en methoden kan zowel (te) hoge of te lage verwachtingen in de hand werken. Uit expertmeetings - gehouden in het kader van het WODC-rapport - blijkt bijvoorbeeld dat neurowetenschappelijke instrumenten door sommigen als objectiever worden beschouwd dan vragenlijsten of interviews. Hoewel neurowetenschappelijke instrumenten minder onder invloed staan van bewuste processen, zoals probleembesef, kunnen de uitkomsten niettemin een vertekend beeld geven wanneer ze zonder context van bijvoorbeeld psychosociale informatie geïnterpreteerd worden. Daarnaast is het waarschijnlijk dat de neurowetenschap nadelen ondervindt van de zwarte bladzijden in de geschiedenis die deze discipline heeft gehad in relatie tot onderzoek naar antisociaal gedrag (Rafter 2008). Termen als 'determinisme' en 'onveranderbaar' zijn lang geassocieerd geweest met biocriminologisch onderzoek. Dergelijke misverstanden zijn weerlegd door wetenschappelijke studies, maar spelen mogelijk nog steeds een rol in de opvatting van personen die verder afstaan van modern biocriminologisch onderzoek (Cornet \& De Kogel 2015). Goede voorlichting aan medewerkers in de strafrechtsketen over de mogelijkheden en beperkingen van neurowetenschappelijke kennis en methoden is belangrijk voor het bereiken van reële verwachtingen.

Neurowetenschappelijke kennis en methoden moeten met goede begeleiding in de praktijk geïntroduceerd worden. In het WODC-rapport pleiten we voor 'pilots in practice', waarin bijvoorbeeld de D2-aandachttest opgenomen wordt en onder begeleiding van onderzoekers in de praktijk verder onderzocht wordt zonder dat er al beslissingen worden genomen op basis van de in de pilot verkregen resulta- 
ten. Op die manier doet de praktijk kennis op met het gebruik van neurowetenschappelijke methoden en kan worden bekeken of de methode inderdaad bijdraagt aan - in dit geval - betere voorspelling van behandeluitval.

Met het uitkomen van het WODC-rapport is veel aandacht gegenereerd voor het aanvullende belang van neurowetenschappelijke kennis in de justitiële praktijk, maar het daadwerkelijk gebruik van neurowetenschappelijke kennis en methoden in de praktijk blijft daar nog bij achter. Dit vraagt om praktijkgericht en verdiepend onderzoek. Verschillende interessante wetenschappelijke studies gericht op het toepasbaar maken van neurowetenschappelijke kennis en methoden zijn momenteel lopende. Zo wordt in de Bascule onderzoek gedaan naar het gebruik van draagbare fysiologische meters om te onderzoeken of een feedbackinstrument kan worden ontwikkeld op basis van fysiologische veranderingen dat jongeren kan helpen bij het onder controle krijgen van gedragsproblemen, zoals agressie. Tevens doet het WODC momenteel onderzoek naar neuropsychologische kenmerken van personen met een licht verstandelijke beperking in de justitiële context. Onderzoek naar neuropsychologische kenmerken bij deze groep biedt op termijn hopelijk handvatten voor meer op maat gesneden bejegening en behandeling.

\section{Referenties}

L.R.A. Alink e.a., 'Cortisol and externalizing behavior in children and adolescents: Mixed meta-analytic evidence for the inverse relation of basal cortisol and cortisol reactivity with externalizing behavior', Developmental Psychobiology 2008, 50, p. 427-50.

A.R. Baskin-Sommers, J.J. Curtin \& J.P. Newman, 'Altering the cognitive-affective dysfunctions of psychopathic and externalizing offender subtypes with cognitive remediation', Clinical Psychological Science 2015, 3, p. 45-57.

K.M. Beaver, M. Ratchford \& C.J. Ferguson, 'Evidence of genetic and environmental effects on the development of low self-control', Criminal Justice and Behavior 2009, 36, p. 1158-1172.

D. Benton, 'The impact of diet on antisocial, violent and criminal behavior', Neuroscience and Biobehavioral Reviews 2007, 31, p. 752-774.

D. Bons e.a., 'Motor, emotional, and cognitive empathy in children and adolescents with autism spectrum disorder and conduct disorder', Journal of Abnormal Child Psychology 2013, 41, p. 425-443.

L. Broomhall, 'Acquired sociopathy: a neuropsychological study of executive dysfunction in violent offenders', Psychiatry, Psychology and Law 2005, 12, p. 367-387.

L.J.M. Cornet \& C.H. de Kogel, 'Is de mens voor een biocriminoloog per definitie onvrij?', Justitiële Verkenningen 2015, 5, p. 50-61.

L.J.M. Cornet e.a., 'Neurobiological factors as predictors of prisoners' response to a cognitive skills training', Journal of Criminal Justice 2015, 43, p. 122-132.

A.A. Duke e.a., 'Revisiting the serotonin-aggression relation in humans: a meta-analysis', Psychological Bulletin 2013, 139, p. 1148-1172.

C.B. Gesch e.a., 'Influence of supplementary vitamins, minerals and essential fatty acids on the antisocial behavior of young adult prisoners: Randomised, placebo-controlled trial', British Journal of Psychiatry 2002, 181, p. 22-28. 
D. Goldman \& F. Ducci, 'The genetics of psychopathic disorders', in: A.R. Felthoud \& H. Sass (red.), International Handbook on Psychopathic Disorders and the Law (Vol.1), West Sussex, VK: Wiley 2007.

S.H.M. van Goozen e.a., 'The evidence for a neurobiological model of childhood antisocial behavior', Psychological Bulletin 2007, 133, p. 149-182.

R.V. Gow \& J.R. Hibbeln, 'Omega-3 fatty acid and nutrient deficits in adverse neurodevelopment and childhood behaviors', Child and Adolescent Psychiatric Clinics of North America 2014, 23, p. 555-590.

T. van Gronde e.a., 'Neurobiological correlates in forensic assessment: A systematic review', PLoS One 2014, 9, p. 1-15.

P.N.S. Hoaken, D.B. Allaby \& J. Earle, 'Executive cognitive functioning and the recognition of facial expressions of emotion in incarcerated violent offenders, non-violent offenders, and controls', Aggressive Behavior 2007, 33, p. 412-421.

K. Hubble e.a., 'Improving negative emotion recognition in young offenders reduces subsequent crime', PLoS One 2015, 10, e0132035.

J. Isen, 'A meta-analytic assessment of Wechsler's $\mathrm{P}>\mathrm{V}$ sign in antisocial populations', Clinical Psychology Review 2010, 30, p. 423-435.

M.W. Lipsey \& F.T. Cullen, 'The effectiveness of correctional rehabilitation: A review of systematic reviews', Annual Review of Law and Social Science 2007, 3, p. 297-320.

A.A. Marsh \& R.J.R. Blair, 'Deficits in facial affect recognition among antisocial populations: A meta-analysis', Neuroscience \& Biobehavioral Reviews 2008, 32, p. 454-465.

T.E. Moffitt, 'The new look of behavioural genetics in developmental psychopathology: Gene environment interplay in antisocial behaviours', Psychological Bulletin 2005, 131, p. 533-554.

R. Narvaes \& R.M. Martins de Almeida, 'Aggressive behavior and three neurotransmitters: dopamine, GABA, and serotonin - a review of the last 10 years', Psychology \& Neuroscience 2014, 7, p. 601-607.

M.K. Nickel e.a., 'Influence of family therapy on bullying behaviour, cortisol secretion, anger, and quality of life in bullying male adolescents: A randomized, prospective, controlled study', Canadian Journal of Psychiatry 2006, 51, p. 355-362.

J.M. Ogilvie e.a., 'Neuropsychological measures of executive function and antisocial behavior: A meta-analysis', Criminology 2011, 49, p. 1063-1108.

R.P. Patrick \& B.N. Ames, 'Vitamin D and the omega-3 fatty acids control serotonin synthesis and action, part 2: Relevance for ADHD, bipolar, schizophrenia, and impulsive behavior', FASEB Journal 2015, 29, p. 2207-2222.

J. Portnoy \& D.P. Farrington, 'Resting heart rate and antisocial behavior: An updated systematic review and meta-analysis', Aggression and Violent Behavior 2015, 22, p. 33-45.

J. Portnoy e.a., 'Heart rate and antisocial behavior. The mediating role of impulsive sensation seeking', Criminology 2014, 52, p. 292-311.

C. van der Put e.a., Ontwikkeling van het Landelijk Instrumentarium Jeugdstrafrechtketen (LIJ), 2011, te raadplegen via www.beke.nl/doc/2011/Ontwikkeling\%20KAP\%202011 -2.pdf.

N. Rafter, The Criminal Brain: Understanding Biological Theories of Crime, New York: New York University Press 2008.

A. Raine, 'Reduction in behavior problems with omega-3 supplementation in children aged 8-16 years: a randomized, double-blind, placebo-controlled, stratified, parallel-group trial', Journal of Child Psychology and Psychiatry 2015, 56, p. 509-520.

D.R. Rosell \& L.J. Siever, 'The neurobiology of aggression and violence', iCNS Spectrum 2015, 20, p. 254-279. 
S. Schoentaler e.a., 'The effect of randomized vitamin-mineral supplementation on violent and non-violent antisocial behavior among incarcerated juveniles', Journal of Nutritional and Environmental Medicine 1997, 7, p. 343-352.

H. Smeijsters e.a., Muziektherapie in de justitiële jeugdinrichtingen en gesloten jeugdzorg: Resultaten van praktijkgericht onderzoek, Heerlen: KenVak Publishers 2012.

D. Terburg, B. Morgan \& J. van Honk, 'The testosterone-cortisol ratio: A hormonal marker for proneness to social aggression', International Journal of Law and Psychiatry 2009, 32, p. 216-223.

S. Verweij, N. Tollenaar \& B.S.J. Wartna, Cova: Eerst denken en dan...? Vergelijkend recidiveonderzoek naar het effect van cognitieve vaardigheidstrainingen uitgevoerd in de periode 2008-2011, Den Haag: Boom juridisch 2016.

B.O. Vogelvang, H. Krooi \& J. van den Braak, Landelijk Kader Instrumentarium Jeugdstrafrechtketen Deel 1: Informatie en samenwerking in de keten, Woerden/Den Haag: Adviesbureau Van Montfoor/Ministerie van Justitie - Directoraat-generaal Preventie Jeugd en Sancties/Jeugd Utrecht 2006.

Y.L. Yang \& A. Raine, 'Prefrontal structural and functional brain imaging findings in antisocial, violent, and psychopathic individuals: A meta-analysis', Psychiatry ResearchNeuroimaging 2009, 174, p. 81-88.

A. Zaalberg e.a., 'Effects of nutritional supplements on aggression, rule-breaking, and psychopathology among young adult prisoners', Aggressive Behavior 2010, 36, p. 117-126. 